\title{
ORIOINAL BESEMRGIARTIGL
}

\section{LEFT VENTRICULAR DYSFUNCTION IN HYPERTENSIVE PATIENTS: AN ECHOCARDIOGRAPHIC ASSESSMENT}

Rishi Khatri ${ }^{1}$, Devendra Khatri ${ }^{1}$, Dhan Bahadur Shrestha ${ }^{1}$, Parag Karki ${ }^{1}$, Chiranjeevi Panta ${ }^{1}$, Raj Kumar Thapa ${ }^{1}$, Binod Karki ${ }^{1}$ ${ }^{1}$ Department of Internal Medicine, Nepalese Army Institute of Health Sciences (NAIHS), Shree Birendra Hospital, Chhauni, Kathmandu

*Correspondence to: Dhan Bahadur Shrestha, Shree Birendra Hospital, Chhauni, Kathmandu, Nepal.

Email: medhan75@gmail.com

\begin{abstract}
Introduction: Echocardiography is noninvasive procedure to assess heart. Ventricular mass increases due to left ventricular hypertrophy and performance of left ventricle decreases with increase in blood pressure. Left ventricular diastolic dysfunction (LVDD) is early sign of heart weakness which can be picked up early with Echo. This study was aimed to study cardiac anatomic and functional parametric alteration in echocardiography among hypertensive patients. Methods: This was a non-invasive, cross sectional hospital based retrospective review of the patient record from echo room among the hypertensive patient who undergone echocardiographic assessment from September 2017-February 2018 in Shree Birendra Hospital (SBH), Chhauni, Kathmandu. Results: Among 447 hypertensive cases, 232(51.9\%) were having normal diastolic function while rest $215(48.1 \%)$ were having diastolic dysfunction of the heart. Among total cases evaluated, only $12(2.7 \%)$ patients were having ejection fraction lower than $55 \%$, while in rest it was normal. There were $53(11.9 \%)$ cases having some form of associated complication. Gender, Concentric Left Ventricular Hypertrophy and left atrial dilatation has significant difference $(p<0.05)$ with LVDD. Statistically significant differences in age distribution of individuals with different categories of left ventricular systolic dysfunction (LVSD) and LVDD $(p<0.001)$ was observed. Conclusion: Significant number of hypertensive individuals were having LVDD though in most of the individual LV ejection fraction was maintained.
\end{abstract}

Key words: Echocardiography, Hypertension, Left ventricular diastolic dysfunction, Nepal

\section{INTRODUCTION}

Echocardiography is noninvasive procedure to assess cardiac anatomic and functional parameters. Ventricular mass increment due to left ventricular hypertrophy, decreased performance of left ventricle (LV) with increasing blood pressure and other parameters can be detected early with echo. ${ }^{1-4}$ Hypertension is top most cause of diastolic dysfunction of heart, affecting elderly contributing to the chunk of heart failure cases..$^{5,6}$ Left ventricular diastolic dysfunction (LVDD) is early sign of heart dysfunction which can be picked up early with precise diagnosis with echocardiographic assessment so, it is necessary to seek early LVDD diagnosis and its prevention to improve the outcome of hypertensive individuals. ${ }^{4,6,7}$
From Nepal, few studies have been done to assess cardiac function in hypertensive patients and showed LVDD in about $60 \%$ of new and never treated essential hypertension which is also seems to be significantly associated with hypertension. ${ }^{8,9}$ This study was aimed to study cardiac anatomic and functional parametric alteration in echocardiography among hypertensive patients presenting to echo in a tertiary center of Kathmandu.

\section{METHODS}

This was a non-invasive, cross sectional hospital based retrospective review of the patient record from echo room among the hypertensive patient who undergone echocardiographic assessment. 
This study was conducted based on echo data among patient who underwent echo in last six months period from September 2017-February 2018 in Shree Birendra Hospital (SBH), Chhauni, Kathmandu. SBH is the only tertiary level hospital for the serving soldiers, veterans and their families where such study has not been done yet. The data of the interest were retrieved from echo room register based on data retrieval sheet after the approval of proposal from local institutional ethical committee of Nepalese army institute of health sciences (NAIHS) and respecting the human and animal rights for research based on Helsinki declaration.

In our center, we first evaluate hypertensive cases with proper history and examination to look for various comorbidities and complications and we plan for echo evaluation. After the diagnosis by consultant as a case of hypertension or already under anti-hypertensive medication; to look for cardiac changes of hypertension we perform echo. All patient of hypertension asymptomatic or with some cardiac symptoms who underwent echo in study period were enrolled in the study. The data collected were for anatomic and functional echo findings of chamber dilatation, increased LV wall thickness, valvular regurgitations, presence of LV systolic and diastolic dysfunction which were evaluated using 2D, M Mode, and Colour wave Doppler. The data obtained was entered in Statistical Package for Social Sciences (SPSS). Various factors of interest and its association with LVDD was analyzed using SPSS version 22 using chi-square test with $5 \%$ standard error with $95 \%$ confidence interval with $p$-value of $<0.05$ as significant. LVDD and LVSD was compared with age using non-parametric tests (Mann-Whitney
U test and Kruskal- Wallis Test) respectively to check the difference in distribution.

\section{RESULTS}

Total 447 patient's data were enrolled for analysis in the present study. The median age of the participants being $50(\mathrm{IQR}=35-66)$ years. Among the studied population, $325(72.7 \%)$ were male while rest $122(27.3 \%)$ were females. Patients were categorized into three group (regular, retired and family) based on their serving status in the army profession. There were 185 (41.4\%) regular and family each and 77 $(17.2 \%)$ retired patients enrolled in the study. (Figure 1.)

\section{SERVING STATUS}

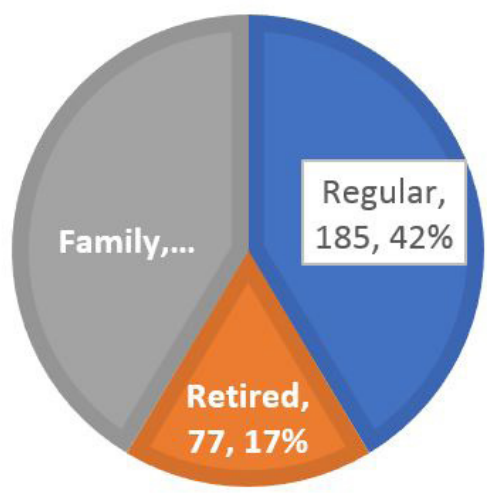

Figure 1. Serving status

There were $53(11.9 \%)$ cases having some form of associated complication other than Hypertension while in rest cases solely hypertension was the comorbidity. COAD and DM were the commonly associated comorbidities (Table 1.)

\section{Table 1: Comorbidities among cases evaluated}

\begin{tabular}{|l|c|c|c|}
\hline Comorbidities & Frequency & Percent & $\begin{array}{l}\text { Cumulative } \\
\text { Percent }\end{array}$ \\
\hline None & 394 & 88.1 & 88.1 \\
\hline Atrial Fibrillation (AF) & 8 & 1.8 & 89.9 \\
\hline AF with hyperthyroidism & 1 & .2 & 90.2 \\
\hline AF with Valvular Heart Disease & 1 & .2 & 90.4 \\
\hline Coronary artery Disease (CAD) & 1 & .2 & 90.6 \\
\hline Chronic Obstructive Airway Disease (COAD) & 18 & 4.0 & 94.6 \\
\hline Chronic Renal failure & 1 & .2 & 94.9 \\
\hline
\end{tabular}




\begin{tabular}{|l|c|c|c|}
\hline Comorbidities & Frequency & Percent & $\begin{array}{l}\text { Cumulative } \\
\text { Percent }\end{array}$ \\
\hline Cerebrovascular Diseases & 2 & .4 & 95.3 \\
\hline Diabetes Mellitus (DM) & 16 & 3.6 & 98.9 \\
\hline DM/COAD & 1 & .2 & 99.1 \\
\hline MI & 1 & .2 & 99.3 \\
\hline Paraplegia & 2 & .4 & 99.8 \\
\hline Seizure & 1 & .2 & 100.0 \\
\hline Total & $\mathbf{4 4 7}$ & $\mathbf{1 0 0 . 0}$ & \\
\hline
\end{tabular}

Among 447 hypertensive cases 232(51.9\%) Hypertrophy (CONCLVH) and left atrial dilatation were having normal diastolic function while rest has significant difference $(p<0.05)$ with LVDD. While 215(48.1\%) were having diastolic dysfunction of other valvular, chamber parameters showed no the heart. Gender, Concentric Left Ventricular significant difference with LVDD. (Table 2.)

Table 2: LVDD status and its relationship with the several parameters

\begin{tabular}{|c|c|c|c|c|c|}
\hline \multirow{2}{*}{\multicolumn{2}{|c|}{ Variables }} & \multicolumn{2}{|c|}{ LVDD } & \multirow{2}{*}{ p-value } & \multirow{2}{*}{ Odds-ratio } \\
\hline & & \multirow{2}{*}{$\begin{array}{l}\text { No } \\
184\end{array}$} & \multirow{2}{*}{$\begin{array}{l}\text { Yes } \\
141\end{array}$} & & \\
\hline \multirow{2}{*}{ Sex } & MALE & & & \multirow{2}{*}{0.001} & \multirow{2}{*}{$\begin{array}{l}2.01(1.31- \\
2.07)\end{array}$} \\
\hline & FEMALE & 48 & 74 & & \\
\hline \multirow{2}{*}{ CONCLVH } & No & 225 & 199 & \multirow{2}{*}{0.034} & \multirow{2}{*}{\begin{tabular}{|l}
$2.58(1.04-$ \\
$6.41)$ \\
\end{tabular}} \\
\hline & YES & 7 & 16 & & \\
\hline \multirow{3}{*}{ Mitral Regurgitation } & NONE & 210 & 196 & \multirow{3}{*}{0.547} & \multirow{3}{*}{-} \\
\hline & MILD & 14 & 15 & & \\
\hline & MODERATE & 8 & 4 & & \\
\hline \multirow{3}{*}{ Aortic Regurgitation } & NONE & 220 & 197 & \multirow{3}{*}{0.396} & \multirow{3}{*}{-} \\
\hline & MILD & 9 & 13 & & \\
\hline & MODERATE & 3 & 22 & & \\
\hline \multirow{4}{*}{ Tricuspid Regurgitation } & NONE & 199 & 184 & \multirow{4}{*}{0.77} & \multirow{4}{*}{-} \\
\hline & MILD & 28 & 26 & & \\
\hline & MODERATE & 5 & 4 & & \\
\hline & SEVERE & 0 & 1 & & \\
\hline \multirow{2}{*}{ Right Atrium } & NORMAL & 228 & 213 & \multirow{2}{*}{0.446} & \multirow{2}{*}{$\begin{array}{l}0.53(0.09- \\
2.95)\end{array}$} \\
\hline & DILATED & 4 & 2 & & \\
\hline \multirow{2}{*}{ Right Ventricle } & NORMAL $(0.7-2.3 \mathrm{CM})$ & 228 & 213 & \multirow{2}{*}{0.446} & \multirow{2}{*}{$\begin{array}{l}0.53(0.09- \\
2.95)\end{array}$} \\
\hline & DILATED & 4 & 2 & & \\
\hline \multirow{2}{*}{ Left Atrium } & NORMAL $(2.0-4.0 \mathrm{CM})$ & 225 & 215 & \multirow{2}{*}{0.01} & \multirow{2}{*}{$\begin{array}{l}0.97(0.94- \\
0.99)\end{array}$} \\
\hline & DILATED & 7 & 0 & & \\
\hline
\end{tabular}




\begin{tabular}{|c|c|c|c|c|c|}
\hline \multirow{2}{*}{\multicolumn{2}{|c|}{ Variables }} & \multicolumn{2}{|c|}{ LVDD } & \multirow{2}{*}{ p-value } & \multirow{2}{*}{ Odds-ratio } \\
\hline & & No & Yes & & \\
\hline \multirow[t]{2}{*}{ Left Ventricle } & $\begin{array}{l}\text { NORMAL }(\mathrm{ED}=3.5-5.6 \\
\mathrm{CM} ; \mathrm{ES}=2.0-4.0 \mathrm{CM})\end{array}$ & 229 & 212 & \multirow[t]{2}{*}{0.925} & \multirow{2}{*}{$\begin{array}{l}1.08(0.21- \\
5.41)\end{array}$} \\
\hline & DILATED & 3 & 3 & & \\
\hline \multirow{2}{*}{ EF reduced } & YES & 6 & 6 & \multirow{2}{*}{.894} & \multirow{2}{*}{$\begin{array}{l}0.92(0.29- \\
2.91)\end{array}$} \\
\hline & NO & 226 & 209 & & \\
\hline
\end{tabular}

Among total cases evaluated, only $12(2.7 \%)$ patients in rest it was normal. (Table 3.) were having ejection fraction lower than $55 \%$, while

Table 3: LVSD among evaluated cases

\begin{tabular}{|l|c|c|}
\hline LVSD & Frequency & Percent \\
\hline None $(\mathrm{EF}>=55 \%)$ & 435 & 97.3 \\
\hline Mild $(\mathrm{EF}=45-54 \%)$ & 7 & 1.6 \\
\hline Moderate $(\mathrm{EF}=30-44 \%)$ & 5 & 1.1 \\
\hline Total & $\mathbf{4 4 7}$ & $\mathbf{1 0 0 . 0}$ \\
\hline
\end{tabular}

There is statistically significant differences in age distribution of individuals with LVDD. (p<0.001) (Figure 2.).
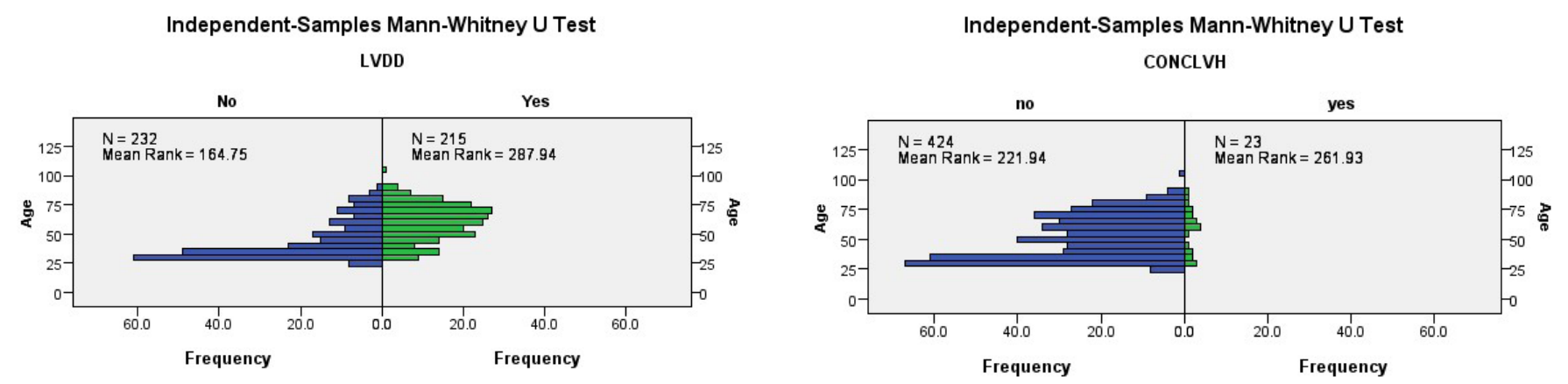

Figure 2. Man-Whitney U test

Also, there is statistically significant differences in age of LVSD $(p<0.001)$ while that for CONCLVH was same distribution of individuals with different categories for age $(p=0.148)$ (Figure 3.).

Independent-Samples Kruskal-Wallis Test

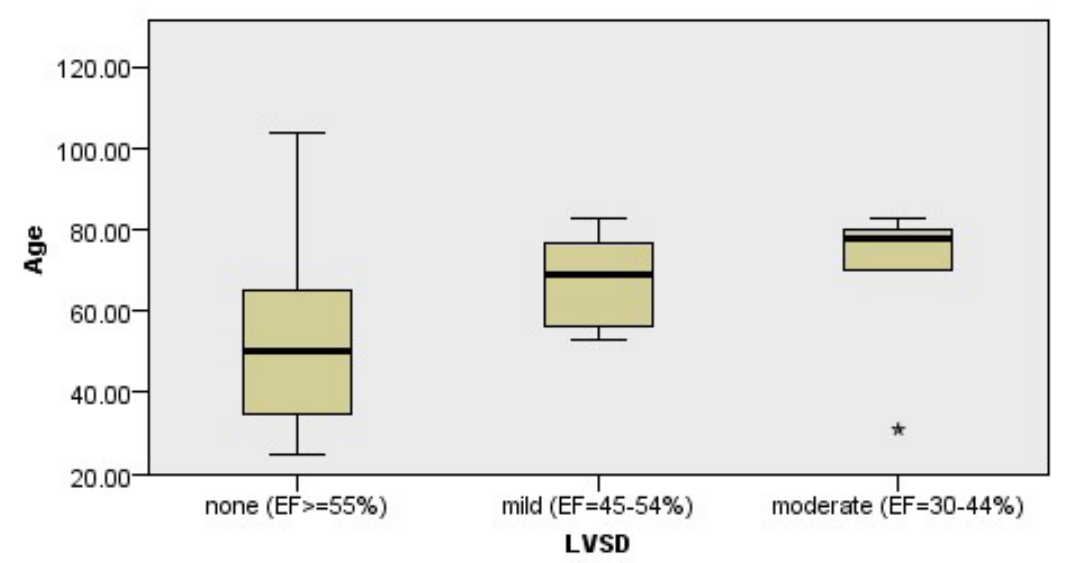

Figure 3. Kruskal-Wallis Test 


\section{DISCUSSION:}

Hypertension is the main determinant of LVDD though other risk factors include diabetes, renal disease etc. Substantial hypertensive individuals tend to have LVDD and the proportion varies based on the study population and the echocardiographic variables ranging from $18-84 \% .{ }^{5}$ In present study there were $48.1 \%$ individuals were having LVDD while only in $2.7 \%$ there were LVSD preserving the ejection fraction suggesting in most of the cases there were isolated diastolic dysfunction. A large cross-sectional observational study showed $25.8 \%$ patients having LVDD based on trans-mitral peak velocities while it was $45.6 \%$ using deceleration time to define LVDD with age, gender, and mass of LV as significant variables comparable to our study. ${ }^{10}$ Hypertension mainly affects relaxation phase of the left ventricle even left ventricular hypertrophy making the low compliance of the left ventricle leading to diastolic dysfunction though left ventricular ejection function may be preserved. ${ }^{6}$ By Echocardiographic assessment we can easily study the left ventricular function and detect the early dysfunction and heart failure accurately in competent hands. ${ }^{2,4}$

In $5.1 \%$ of the cases there was concentric left ventricular hypertrophy observed through echo in our study population. There were $15-46 \%$ of the hypertensive patients having LVH in different study population in echo findings. ${ }^{5,8}$ In present study the median age of the participants was 50 years with predominance of male. Similarly, another study conducted in Nepal also revealed mean age of 50 with male predominance suggesting the hypertension is common with elderly and male who have more chances of getting enroll in echocardiographic examination. ${ }^{9}$

Studies have shown that higher age, reduced $E F$, obesity, history of hypertension, diabetes, myocardial infarction as predictors of diastolic dysfunction. ${ }^{11}$ Also, heart failure and left ventricular diastolic dysfunction is common in elderly age group..$^{12}$ In another Indian study, there was LVDD in $55.70 \%$ of $30-60$ years hypertensive individuals with significant association with elderly age and LVDD and progression of LVDD with sedentary lifestyle. ${ }^{13}$ Which is also fairly true with our case showing significant difference in age distribution with LVDD and LVSD showing more elder with heart dysfunction. With time, adjusting the contributory variables diastolic dysfunction itself is associated with heart failure so it should be timely diagnosed and manage appropriately to prevent myocardial remodeling in time. ${ }^{14}$ Antihypertension therapy to reduce blood pressure to the target will reduce cardiac load, which will regress $\mathrm{LVH}$, and its progression and improve cardiac function. ${ }^{15}$

This was retrospective study based on limited data available from echo data records so further larger prospective study with more variables need to be done to add more in the topic.

\section{CONCLUSION}

Significant number of hypertensive individuals were having LVDD though in most of the individual LV ejection fraction was maintained. There is significant difference $(p<0.05)$ between gender, CONCLVH and left atrial dilatation with LVDD. Also, there is statistically significant differences in age distribution of individuals with different categories of LVSD and LVDD $(p<0.001)$ while it was same with CONCLVH $(p=0.148)$.

\section{REFERENCES}

1. Dunn FG, Chandraratna P, Jose GR, Basta LL, Frohlich ED. Pathophysiologic assessment of hypertensive heart disease with echocardiography. Am J Cardiol. 1977;39(6):78995. DOI: https://doi.org/10.1016/S00029149(77)80028-3

2. Black HR, Weltin G, Jaffe CC. The limited echocardiogram: a modification of standard echocardiography for use in the routine evaluation of patients with systemic hypertension. Am J Cardiol. 1991;67(11):1027-30. DOI: https://doi. org/10.1016/0002-9149(91)90178-N

3. Wachtell K, Smith G, Gerdts E, Dahlöf B, Nieminen MS, Papademetriou V, Bella JN, Ibsen H, Rokkedal $J$, Devereux RB. Left ventricular filling patterns in patients with systemic hypertension and left ventricular hypertrophy (the LIFE study). Am J Cardiol. 2000;85(4):466-72. DOI: https://doi. org/10.1016/S0002-9149(99)00773-0 
4. Dokainish H. Left ventricular diastolic function and dysfunction: central role of echocardiography. Glob Cardiol Sci Pract. 2015;1:3. DOI: https:// doi.org/10.5339/gcsp.2015.3 PMid:25830147 PMCid:PMC4374097

5. Nadruz W, Shah AM, Solomon SD. Diastolic dysfunction and hypertension. Med Clin. 2017;101(1):7-17. DOI: https://doi. org/10.1016/j.mcna.2016.08.013

6. Palmiero $P$, Zito $A$, Maiello $M$, Cameli $M$, Modesti PA, Muiesan ML, Novo S, Saba PS, Scicchitano P, Pedrinelli R, Ciccone MM. Left ventricular diastolic function in hypertension: methodological considerations and clinical implications. J Clin Med Res. 2015;7(3):137. DOI: $\quad$ https://doi.org/10.14740/jocmr2050w PMid:25584097 PMCid:PMC4285058

7. AvdićS, MujčinovićZ, Ašćerić $M$, NukićS, Kušljugić Z, Smajić E, Arapčić S. Left venticular diastolic dysfunction in essential hypertension. Bosnian journal ofbasicmedicalsciences. 2007;7(1):15-20. DOI: https://doi.org/10.17305/bjbms.2007.3082 PMid:17489762 PMCid:PMC5802280

8. Gajurel RM, Sayami A. Prevalence of Left ventricular diastolic dysfunction in newly diagnosed and never treated essential hypertension in tertiary care Hospital of Nepal. J Inst Med. 2016;39(1).

9. Laudari S, Dhungel S, KC PJ, Prasad G, Bhattacharya R, Subramanyam G. Study of left ventricular diastolic dysfunction in recently diagnosed hypertensives in Central Nepal. J Coll Med Sci Nep. 2016;12(1):14-8. DOI: https://doi. org/10.3126/jcmsn.v12i1.14682

10.Zanchetti A, Cuspidi C, Comarella L, Rosei
EA, Ambrosioni $E$, Chiariello $M$, Leonetti $G$, Mancia G, Pessina AC, Salvetti A, Trimarco B. Left ventricular diastolic dysfunction in elderly hypertensives: results of the APROS-diays study. J Hypertens. 2007;25(10):2158-67. DOI: http:// dx.doi.org/10.1097/HJH.0b013e3282eee9cf

11. Abhayaratna WP, Marwick TH, Smith WT, Becker NG. Characteristics of left ventricular diastolic dysfunction in the community: an echocardiographic survey. Heart. 2006;92(9):1259-64. DOI: http://dx.doi. org/10.1136/hrt.2005.080150

12. van Riet EE, Hoes AW, Wagenaar KP, Limburg A, Landman MA, Rutten FH. Epidemiology of heart failure: the prevalence of heart failure and ventricular dysfunction in older adults over time. A systematic review. Eur J Heart Fail. 2016;18(3):242-52. DOI: https://doi. org/10.1002/ejhf.483

13. Ratnaparkhe V, Bhangale A. Left Ventricular Diastolic Dysfunction in Primary Hypertension and its Relation with Leisure Time Physical Activity. J Assoc Physicians India. 2015;63(7):204. PMID: 26731823

14. Kane GC, Karon BL, Mahoney DW, Redfield MM, Roger VL, Burnett JC, Jacobsen SJ, Rodeheffer RJ. Progression of left ventricular diastolic dysfunction and risk of heart failure. JAMA. 2011;306(8):856-63. DOI: https://doi. org/10.1001/jama.2011.1201 PMid:21862747 PMCid:PMC3269764

15. Simone GD, Palmieri V. Diastolic dysfunction in arterial hypertension. J Clin Hypertens. 2001;3(1):22-7. DOI: https://doi.org/10.1111/ j.1524-6175.2001.00827.x 